\title{
El framing como proyecto de investigación: una revisión de los conceptos, ámbitos y métodos de estudio
}

\section{Framing as a research project: a review of concepts, fields, and methods of study}

\author{
Carlos Muñiz
}

Cómo citar este artículo:

Muñiz, Carlos (2020). "El framing como proyecto de investigación: una revisión de los conceptos, ámbitos y métodos de estudio". Profesional de la información, v. 29, n. 6, e290623.

https://doi.org/10.3145/epi.2020.nov.23

Artículo invitado recibido el 10-12-2020

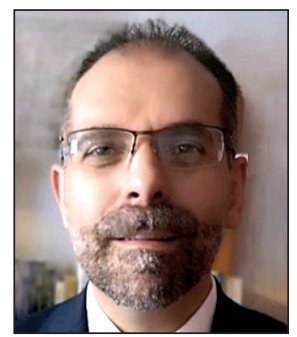
Carlos Muñiz
https://orcid.org/0000-0002-9021-8198
Universidad Autónoma de Nuevo León
Facultad de Ciencias Políticas y Relaciones Internacionales
Campus Mederos, Av. Praga y Trieste, s/n
Colonia Residencial Las Torres
64930 Monterrey (Nuevo León), México
carlos.munizm@uanl.mx

\section{Resumen}

Desde que la teoría del framing se incorporó a los estudios de la comunicación, su utilización por parte de los investigadores se ha incrementado de forma constante, tanto para estudiar la presencia de los encuadres dentro del proceso comunicativo en su conjunto, como sobre todo en las partes que lo conforman. En este artículo se realiza un repaso de la evolución de la teoría en la disciplina, prestando especial atención a algunos aspectos relevantes. En concreto, se recuperan las principales propuestas de tipologías de encuadres existentes, y se revisa el debate sostenido acerca de la visualización del framing como un programa o proyecto de investigación, y de los campos de su estudio. Además, en el texto se revisa la lógica de la investigación en los tres principales campos de estudio de la teoría: construcción de los encuadres, presencia de encuadres noticiosos en los mensajes, y efectos que el framing tiene sobre la audiencia, haciendo una revisión de los acercamientos metodológicos seguidos en cada una de esas líneas de trabajo.

\section{Palabras clave}

Framing; Proyectos de investigación; Encuadres noticiosos; Construcción del encuadre; Establecimiento del encuadre; Efectos de los encuadres; Campos de estudio; Métodos de estudio; Revisión; Investigación en comunicación.

\begin{abstract}
Since framing theory was incorporated into Communication studies, its use by researchers has increased steadily, to study the presence of frames both within the communicative process and especially in the different parts thereof. This paper reviews the evolution of this theory within Communication, paying special attention to various relevant aspects. Specifically, the main proposals for existing frame typologies are extracted and discussed. The debates about the visualization of framing as a research program or project as well as the fields in which it is studied are reviewed. In addition, this paper reviews the logic of such research in the three main fields of study within the theory: frame building, the presence of news frames in messages, and the framing effects on the audience, providing a review of the methodological approaches followed in each of these lines of work.
\end{abstract}

\section{Keywords}

Framing; News frames; Research projects; Frame building; Frame setting; Framing effects; Fields of study; Methods of study; Review; Communication research. 


\section{Introducción}

No cabe duda del especial papel que juegan los medios de comunicación al trasladar y, en muchas ocasiones, traducir a la ciudadanía la información referente a las diferentes posturas existentes acerca de los asuntos de importancia, así como los debates suscitados en torno a ellos por los actores involucrados. Gracias a esta información el ciudadano puede tomar sus decisiones, contribuyendo de esta manera al establecimiento de la opinión pública (Matthes, 2012). Dentro de esta labor de transmisión y traducción de los acontecimientos, una herramienta crucial con la que cuentan los medios es el framing, a partir del cual pueden dotar de un determinado tratamiento informativo al contenido de sus noticias para narrar la realidad social (De-Vreese, 2005; 2012). En este sentido, los periodistas elaboran sus noticias valiéndose de diferentes encuadres o enfoques con los que pueden ofrecer ese tratamiento informativo particular de la realidad (D’Angelo, 2002; De-Vreese, 2003; Entman, 1993; Matthes, 2012). Es decir, los encuadres noticiosos o frames constituyen la manera como los acontecimientos son presentados a través de los mensajes informativos, enfatizando o excluyendo posibles aspectos de la realidad existente (De-Vreese, 2005; Semetko; Valkenburg, 2000).

Los trabajos seminales realizados a partir de los años 80 y 90 del siglo XX por autores como Entman (1993) o Tankard (2001), entre otros, fueron clave para la incorporación de la teoría del framing dentro de los estudios de las ciencias de la comunicación. La capacidad demostrada por ésta para explicar los procesos, no sólo de construcción de la opinión publicada, sino también de determinación de la opinión pública (De-Vreese, 2005), ha contribuido a que en los últimos años se haya posicionado como uno de los acercamientos teóricos predominantes en la bibliografía en comunicación desarrollada acerca de muy variadas temáticas (Borah, 2011; Cacciatore; Scheufele; Iyengar, 2016; Saperas; Carrasco-Campos, 2015). En este sentido, son numerosos los estudios realizados con el objetivo de detectar los encuadres noticiosos empleados en los medios para presentar las noticias principalmente desde análisis de contenido (Ardèvol-Abreu, 2015), así como también los que buscan determinar la influencia que el consumo de los encuadres tiene en la modificación de las actitudes y comportamientos de la audiencia (Brugman; Burgers, 2018), en su mayoría desde acercamientos experimentales (De-Vreese, 2012).

Teniendo en cuenta lo anteriormente expuesto, el objetivo de este artículo es realizar un repaso de la evolución de la teoría en la disciplina, prestando especial atención a algunos aspectos relevantes. Cabe mencionar que el desarrollo de la investigación acerca del framing es tan amplio y se desarrolla desde disciplinas y paradigmas tan dispares que sería imposible sintetizar en un texto toda la riqueza que acompaña a su estudio. Por ello, y sin ánimo de agotar todo el debate que se puede generar en torno a la teoría, en las siguientes páginas se expondrán algunos aspectos que se consideran importantes para entender su evolución y sus ámbitos de desarrollo de la investigación. En particular, se hace un repaso a las etapas por las que se ha determinado que han transitado los estudios de framing, se revisan algunos de los tipos de encuadres existentes y se hace mención del debate sostenido acerca de la visualización de la teoría como un programa o proyecto de investigación. Además, en el texto se abordan los campos principales de estudio de la teoría: la construcción de los encuadres, la presencia de encuadres noticiosos en los mensajes y los efectos que el framing tiene sobre la audiencia.

\section{La teoría del framing dentro de los estudios de la comunicación}

Una rápida revisión a las principales revistas vinculadas con las ciencias de la comunicación permite llegar a una conclusión clara: la teoría del framing emerge en buena parte de ellas como uno de los planteamientos teóricos más ampliamente utilizados por los investigadores del campo para realizar sus proyectos de investigación. No en vano la teoría se ha posicionado como uno de los acercamientos teóricos predominantes en la bibliografía en comunicación (Brugman; Burgers; Steen, 2017; De-Vreese, 2005) y sus diferentes subdisciplinas (Cacciatore et al., 2016) a nivel internacional, algo de lo que por supuesto tampoco ha escapado la práctica investigadora en el contexto español y el latinoamericano (Ardèvol-Abreu, 2015; Piñeiro-Naval; Morais, 2020; Sádaba-Garraza; Rodríguez-Virgili; Bartolomé-Castro, 2012; Saperas; Carrasco-Campos, 2015; Valera-Ordaz, 2016), Vicente-Mariño; López-Rabadán, 2009).

Desde que autores como Tankard (2001), Reese (2001) o

Entman (1993) incorporasen el concepto y la perspectiva teórica del framing dentro de los estudios de ciencias de la comunicación, son numerosas las investigaciones llevadas a cabo tomando como base esta teoría para analizar las diferentes fases que implica el proceso comunicativo.

Ello se ha puesto de manifiesto en las revisiones bibliográficas y análisis bibliométricos realizados acerca de la utilización de la teoría hasta la fecha. Es el caso de los trabajos de Bryant y Miron (2004) o de Weaver (2007), que reflejan que entre 2001 y 2005 se publicaron más del doble de artículos en revistas internacionales que los difundidos entre 1996 y 2000 tomando el framing como base teórica. Esta fuerte implantación dentro de la disciplina es nuevamente corroborada por Saperas y Carrasco-Campos (2015), quienes detectaron que sólo entre 2009 y 2013 Journal of communication, revista de referencia en la disciplina, publicó 50 artículos sobre framing, a razón de casi dos textos por número en promedio.

Esta popularidad ganada por la teoría en la bibliografía de la disciplina a finales del siglo XX y principios del XXI (De-Vreese, 2005; Reese, 2007) no ha hecho más que incrementarse, como se puede observar a tenor de los datos antes descritos. Algo que ha llevado a que actualmente se establezca, en palabras de Saperas y Carrasco-Campos (2015), "como programa empírico ampliamente dominante" (p. 51) en los estudios de comunicación a nivel internacional. Así, es habitual 
que en las principales revistas del campo se pueda encontrar al menos un artículo sobre framing (Scheufele; Iyengar, 2017), desde el que se aborde cualquiera de los procesos que implican la construcción y transmisión de los mensajes, o de sus efectos sobre la opinión pública. En el caso de España, si bien su estudio se encuentra en una fase inicial en comparación a su desarrollo en otros contextos geográficos (Ardèvol-Abreu, 2015), se puede observar un constante crecimiento de estudios elaborados desde el framing (Piñeiro-Naval; Mangana, 2019). Algo extrapolable al contexto latinoamericano, aunque aún en un nivel de desarrollo inferior (Piñeiro-Naval; Morais, 2020).

Un examen rápido de la bibliografía de la disciplina de comunicación basada en la teoría permite ver la multiplicidad de tópicos estudiados, así como de acercamientos metodológicos implementados para su aplicación. Ello se ha debido, en gran medida, a la fuerte interdisciplinariedad que presenta en su aplicación, que ha llevado a ser utilizado ampliamente en varias disciplinas académicas (Borah, 2011; D’Angelo, 2002; 2012). Así, no es raro que se puedan encontrar estudios en disciplinas como la ciencia política, la comunicación, la psicología, la sociología, entre otras (Brugman; Burgers, 2018; Reese, 2018), vinculados a muy variadas temáticas y asuntos de estudio. Por ejemplo, Brugman, Burgers y Steen (2017) detectaron recientemente en su revisión estudios centrados en economía, salud, medio ambiente, educación o negocios, únicamente en el campo de la comunicación política.

Y es que, si bien la teoría se ha infiltrado en distintas disciplinas de las ciencias sociales y, en particular, en las subdisciplinas de la comunicación, es en el campo de la comunicación política donde ha encontrado un ambiente más fecundo para su desarrollo. Un repaso a los estudios realizados en comunicación política la ubican como el campo de investigación con mayor presencia de estudios sobre framing a nivel internacional (Brugman et al., 2017; Cacciatore et al., 2016; Matthes, 2009; Piñeiro-Naval; Mangana, 2019; Sádaba-Garraza et al., 2012). Esto queda demostrado con trabajos bibliométricos como el publicado por Saperas y Carrasco-Campos (2015) acerca de la presencia de la teoría en los trabajos publicados por la revista Journal of communication o el reciente de Piñeiro-Naval y Morais (2020) en las revistas hispánicas de comunicación, donde el framing vuelve a emerger como una teoría con fuerte presencia en los estudios sobre política.

Quizá una justificación a esta gran aplicabilidad que la teoría tiene en tan variadas disciplinas radique en sus orígenes multidisciplinares. No en vano, como recuerda D’Angelo (2018a), el framing constituye un constructo con raíces profundas tanto en las ciencias sociales como en las humanidades, lo que posibilita su estudio por investigadores desde postulados teóricos y metodológicos diferentes. Es el caso de la comunicación, donde el concepto se ha nutrido, y sigue haciéndolo, tanto de la psicología como de la sociología (Borah, 2011; Entman, 1993; D’Angelo, 2002; Lecheler; De-Vreese, 2016). Más allá de la reciente crítica que se está haciendo del abandono de la perspectiva psicológica, que propugna la comprensión del encuadre desde la equivalencia (Scheufele; Iyengar, 2017), no cabe duda de que ha sido la perspectiva sociológica la que ha triunfado en los estudios, en la que prima la idea del encuadre enfatizado.

Es precisamente en el acercamiento sociológico donde se sitúa la definición del framing realizada por Entman (1993), que posiblemente es la más utilizada por los investigadores para describir el proceso que implica el tratamiento de la información. De acuerdo con el autor, éste conlleva

"seleccionar algunos aspectos de la realidad percibida y hacerlos más relevantes en un texto comunicativo, de modo que se promueva una determinada definición del problema, una interpretación causal, una evaluación moral y/o una recomendación de tratamiento para el asunto descrito" (p. 52).

Se observa, por tanto, cómo desde el framing no se aborda el estudio de los asuntos en sí, un planteamiento más propio de otras teorías dentro de la disciplina, sino más bien la manera como se presentan esos asuntos a partir del énfasis que se ofrece en los mensajes de los diferentes aspectos que describen el asunto en concreto (De-Vreese, 2005). A partir de estos planteamientos iniciales ha sido abundante la bibliografía empírica sobre la teoría que se ha acumulado, lo que supone un reto de integración y sistematización teórica que permita comprender el progreso del concepto dentro de la disciplina (D’Angelo, 2019).

\section{Evolución del framing dentro de la investigación en comunicación}

La presencia de la teoría del framing en investigación de la comunicación ha pasado por diferentes etapas o fases históricas. Al respecto, Vicente-Mariño y López-Rabadán (2009) señalan que se pueden visualizar tres fases en las que la teoría como apoyo para la realización de investigación en comunicación ha transitado por diferentes roles.

1) La primera, que según los autores se puede situar entre los años 70 y principios de los 90 del siglo XX, es una etapa de reflexión acerca de las posibilidades que el framing, como proceso y concepto definido y utilizado en otras disciplinas como la sociología y la psicología, podría tener para los estudios realizados desde las ciencias de la comunicación acerca del proceso comunicativo. En esta etapa se pueden encontrar las primeras referencias dentro de los estudios en comunicación a nivel internacional (Borah, 2011), normalmente tomando el framing como concepto prestado desde otras "disciplinas solidarias" (Saperas; Carrasco-Campos, 2015, p. 50), tales como la psicología, la sociología interpretativa, la fenomenología o el interaccionismo simbólico.

2) Sin embargo, es a partir de los años 90 cuando se observa una presencia más fuerte del framing dentro de la bibliografía sobre comunicación. Esta década es para Vicente-Mariño y López-Rabadán (2009) la segunda etapa de desarrollo 
dentro de las ciencias de la comunicación. Una etapa marcada por el trabajo seminal de Entman (1993) dentro del monográfico de Journal of communication dedicado a debatir sobre el estado disciplinario de la investigación en comunicación, y que constituye uno de los principales puntos de referencia para los investigadores del framing en comunicación, pues plantea la definición que ha ofrecido mayor sustento a su estudio en la disciplina. Esta etapa vendría marcada por dos debates de corte conceptual. En primer lugar, el derivado de la necesidad de aclarar conceptualmente nuevos términos, como framing o frame. En este contexto emergen preguntas como ¿qué se debe entender por framing? o ¿qué es un frame? dentro de los estudios, sin duda influidos por la concepción de paradigma fracturado con el que Entman (1993) lo definió en su trabajo.

El segundo debate conceptual, con un amplio intercambio de propuestas a nivel teórico, se centró en la posible asimilación del framing al segundo nivel de la agenda (Carragee; Roefs, 2004; Saperas; Carrasco-Campos, 2015; Scheufele, 1999). Y es que, a partir del planteamiento del segundo nivel de la agenda a mediados de los 90 se suscitó un importante debate entre los estudiosos de la comunicación acerca de la posible convergencia del estudio de la agenda de los atributos propio del agenda setting y la investigación sobre los encuadres noticiosos, lo que para autores como Carragee y Roefs (2004) claramente indicaba una simplificación del framing al ignorar toda la variedad temática que se había planteado en las definiciones hechas del concepto hasta ese momento. Este debate se cierra en buena medida con el número especial sobre la teoría publicado en Journal of communication en 2007 que lo consolida como modelo teórico reconocible dentro de la disciplina con entidad propia (De-Vreese, 2005).

3) Con la llegada del nuevo siglo, el framing alcanza la tercera etapa del desarrollo en la comunicación, que según Vicente-Mariño y López-Rabadán (2009) evoluciona desde el año 2000 hasta la actualidad y está centrada en la reorganización teórica de la especialidad. Esta etapa viene marcada por una clara tendencia al aumento de la producción de la investigación en comunicación tomando a la teoría como único acercamiento teórico o bien en relación con otros. En esta etapa, donde se asume

"el estatus del framing como programa empírico ampliamente dominante" (Saperas; Carrasco-Campos, 2015, p. 51),

se busca clarificar conceptual y metodológicamente la especialidad desde visiones globales, lo que llevó al planteamiento de modelos para explicar las relaciones entre los frames presentes en las diferentes etapas del proceso. Lo que no ha impedido, sin embargo, que se abran nuevas discusiones teóricas acerca de la naturaleza del framing, entendiéndolo más como un proceso de énfasis de aspectos de la realidad, o de presentación de piezas exactas o equivalente de información, donde para autores como Scheufele e lyengar (2017) se encuentra el fundamento original del proceso del framing.

\section{Tipos de encuadres}

A pesar del asentamiento que el framing ha tenido como acercamiento teórico dominante dentro de la disciplina en los últimos años (Saperas; Carrasco-Campos, 2015), aún se mantiene una indefinición acerca del objeto de estudio de esta corriente de investigación, es decir, del frame o encuadre en la traducción más extendida al español del término (De-Vreese, 2012; Scheufele, 1999, 2000). Y es que, como recuerdan Lecheler y De-Vreese (2016), aunque el concepto se ha usado por décadas en la investigación en comunicación, la pregunta acerca de qué constituye un frame aún se mantiene sin una respuesta clara. Un problema de conceptualización y operacionalización que radica en múltiples motivos. Por una parte, las numerosas definiciones realizadas por los investigadores hasta la fecha que impiden una uniformidad en cuanto a su conceptualización. A lo que, además, se suma el hecho de que éstas se vean influidas por sus diferentes antecedentes teóricos, lo que para Borah (2011) supone tanto una bendición como una maldición para la teoría.

Así, mientras que las definiciones que surgen del enfoque más sociológico se focalizan en el uso de los símbolos y la transmisión de imágenes de la realidad en los mensajes, desde un acercamiento más psicológico al framing se realizan definiciones del frame centradas en los cambios en las estructuras cognitivas a nivel individual producidas por esos mensajes (Borah, 2011; Chong; Druckman, 2007). Partiendo de estos dos planos de aplicación de la teoría, Druckman (2001) plantea la existencia de dos posibles encuadres. Por una parte, el encuadre en la comunicación (frame in communication), que se centra en las palabras, imágenes, frases y estilo de presentación utilizados al transmitir la información. Por la otra el encuadre en el pensamiento (frame in thought), utilizado para la comprensión individual de la información a nivel cognitivo. Por su parte, Entman (1993) señala en su artículo que los encuadres se pueden encontrar en cuatro posibles localizaciones dentro del proceso comunicativo: en el emisor del mensaje, dentro del mensaje, en el receptor y en la cultura.

Cabe destacar que desde temprano se plantearon dos visiones acerca de la configuración de los frames y de sus posibles efectos sobre la audiencia (Druckman, 2001; Entman; Matthes; Pellicano, 2009). Por una parte, se planteó la existencia de encuadres equivalentes, que remiten a la utilización de conceptos o palabras para elaborar mensajes que, aun siendo diferentes, se presentan como lógicamente equivalentes (Druckman, 2001). Es decir, el frame se entiende como una etiqueta informativamente equivalente, que ofrece sutiles variaciones en el modo de presentación de la noticia (Scheufele; Iyengar, 2017). Esta visión, que sigue los planteamientos realizados por Kahneman y Tversky (1984) desde la teoría de la prospectiva (prospect theory), se centra normalmente en la construcción del mensaje a través del uso del encuadre negativo o de pérdidas (loss frame) frente al positivo o de ganancias (gain frame), los cuales son equivalentes 
en su constitución pero diferentes en los efectos provocados (Borah, 2011; Brugman; Burgers, 2018). Esto llevaría, por ejemplo, a presentar en el mensaje los efectos de una política pública en términos de una ganancia para el $80 \%$ de la población o bien como una pérdida para el $20 \%$ restante.

Con respecto a este enfoque más psicológico de la teoría, se ha apuntado que su concepción del proceso del framing limita su aplicabilidad dentro del contexto social o político (Lecheler; De-Vreese, 2016), haciendo que de hecho sea muy difícil el poder encontrar el uso de los frames equivalentes en la práctica periodística real, donde suelen dominar los encuadres enfatizados (Druckman, 2001). Desde esta otra visión, se asume que el mensaje se construye enfatizando un subconjunto de potenciales y relevantes consideraciones del asunto. Una idea claramente plasmada por Tankard (2001) al definir el encuadre como

"la idea organziadora central del contenido de las noticias, que proporciona un contexto y presenta el asunto a través del uso de la selección, énfasis, exclusión y elaboración" (p. 100).

Es decir, se asume que el mensaje tiende a presentar el asunto desde consideraciones potencialmente relevantes, aunque cualitativamente diferentes, que ponen de manifiesto la complejidad del asunto cubierto (Chong; Druckman, 2007).

A pesar de que los encuadres enfatizados sean los dominantes en los estudios sobre framing (Lecheler; De-Vreese, 2016), aún se mantiene una discusión acerca de qué tipos de encuadres deberían ser estudiados y aplicados en los estudios apoyados en la teoría (Brugman; Burgers, 2018). Es el caso de la propuesta de Cacciatore et al. (2016), quienes propugnan la necesidad de un cambio de paradigma en la investigación acerca del proceso del framing para volver más a una definición del mismo que retome la base psicológica de la equivalencia en la presentación de los acontecimientos, abandonando así el tradicional uso de los frames enfatizados. Esta es una postura también mantenida por Scheufele e lyengar (2017) para quienes el uso de los encuadres enfatizados supone una pérdida de la definición original del framing que tiene su naturaleza en la equivalencia. Además, para los autores los efectos de los encuadres enfatizados se confunden con los producidos por modelos sobre efectos planteados desde otros acercamientos teóricos, como la agenda setting o el priming, que basan la naturaleza el efecto en el énfasis dado al mensaje o los asuntos narrados en el mismo.

Tomando como referencia parte de las clasificaciones previas de los encuadres existentes, D’Angelo (2018b) establece una tipología que describe de forma amplia los diferentes encuadres que se presentan dentro del proceso del framing y que han sido centrales en los estudios realizados hasta la fecha en sus diferentes campos de aplicación. En su clasificación, el autor señala la existencia de los

- frames de asunto (issue frame) también conocidos como de promoción (advocacy frame);

- frames periodísticos;

- frames noticiosos; y

- frames de la audiencia (audience frames), cognitivos, del individuo o frames en el pensamiento.

Cada uno de estos encuadres abre la posibilidad de un proceso de investigación amplio que implique, tanto el estudio en profundidad de su uso dentro del proceso comunicativo, como de las relaciones existentes entre ellos, donde los encuadres pueden adoptar tanto un rol de variable dependiente como de variable independiente, en función de los efectos que se busque explicar (De-Vreese, 2003; Scheufele, 1999; 2000).

En cuanto a los denominados por D’Angelo (2018b) como frames de asunto (issue frames), éstos son los encuadres establecidos a través de sus discursos por los actores que tienen la capacidad de construir y aportar al debate público sus razones para apoyar un lado u otro del asunto sobre el que se está debatiendo. Este encuadre ha sido normalmente definido como encuadre de promoción (advocacy frame), utilizado habitualmente por la élite política para trasladar a otros actores, principalmente los medios de comunicación, sus puntos de vista acerca los asuntos de actualidad (De-Vreese, 2012). Es decir, son los conjuntos o

"paquetes consistentes de argumentos temáticos originalmente propuestos por oponentes y proponentes en el debate político" (Matthes, 2012, p. 254).

Estos encuadres tendrán una relación directa con los periodísticos (journalistic frames), utilizados por los periodistas en el terreno de la comunicación para enfocar la información transmitida por las fuentes (De-Vreese, 2012), ofreciendo de esta manera un contexto para comprender, interpretar así como expresarse acerca de los asuntos transmitidos por los medios (D’Angelo, 2018b).

Habitualmente se define el framing como un proceso de creación, selección y establecimiento de frames por parte de los periodistas (Semetko; Valkenburg, 2000), a quienes corresponde seleccionar y utilizar ciertos encuadres periodísticos (journalistic frames) para presentar los acontecimientos políticos a la sociedad. Se observa, por tanto, que implica seleccionar ciertos encuadres dentro de los textos de las noticias para estructurar la información y darle sentido, destacando las posiciones que se mantienen ante algún tema (De-Vreese, 2012; Matthes, 2012). Esto implica la traslación de los encuadres periodísticos en encuadres noticiosos (news frames), que según D’Angelo y Shaw remiten a las 
"diferentes modalidades de mensaje escrito, hablado, gráfico y visual que los periodistas utilizan para contextualizar un evento, asunto y/o actores dentro de una o más noticias" (D’Angelo; Shaw, 2018, p. 214).

En este sentido, mientras que el encuadre periodístico habría que buscarlo en el seno de medios, donde se ponen en relación los encuadres del periodista con los de las redacciones (Scheufele, 2006), los encuadres noticiosos se encuentran en los mensajes que llegan a la audiencia.

Desde los estudios del framing se ha abordado ampliamente el proceso por el que los medios ayudan al establecimiento del encuadre en el pensamiento de las personas (Druckman, 2001). Este constituye el último de los encuadres planteado por D'Angelo (2018b) dentro de su tipología: el encuadre de la audiencia (audience frame).

También conocido como frame cognitivo, describe la percepción individual de una situación particular, es decir, se revela qué entiende la persona como relevante de la información recibida para poder comprender la situación narrada (Druckman, 2001), lo cual es establecido, reforzado y revisado a través de procesos de socialización y se hace presente mediante las conversaciones, discusiones y/o debates mantenidos por las personas (D’Angelo, 2018b). Precisamente dentro de este apartado se puede insertar la definición realizada por Reese (2001) acerca de los encuadres, al definirlos como

"principios organizadores socialmente compartidos y persistentes en el tiempo, que trabajan simbólicamente para estructurar el mundo social de modo significativo" (p. 11).

\section{El framing como proyecto de investigación}

Cuando Entman (1993) se refiere al framing como un paradigma de investigación, lo hace sin embargo para definirlo como un paradigma fracturado al carecer de un concepto sólido y comprensivo que permita guiar la investigación. Esta realidad, más allá de una debilidad, constituye para autores como D’Angelo (2002) o Reese (2018) precisamente una de sus principales fortalezas, entendiendo que no es posible ni deseable que haya un único paradigma para la comprensión y estudio del proceso comunicativo que implica. Ello debido a que posee una clara naturaleza interdisciplinar, a tenor de las diferentes disciplinas que lo han conformado como un espacio teórico de encuentro para los acercamientos teóricos y metodológicos que lo estudian (Brugman et al., 2017; Matthes, 2009). Paradigmas como el cognitivo, el constructivista o el crítico encuentran en el framing un punto de confluencia (D’Angelo, 2002; 2012; 2019) que, como señala Reese (2018), quizá no pudiera haberse dado fuera de este espacio común, a lo que contribuye precisamente el hecho de constituirse en un paradigma fracturado.

Se observa, por tanto, que la teoría constituye una especie de puente que permite unir partes del campo que necesitan estar en contacto entre ellas: los acercamientos metodológicos (cuantitativos y cualitativos), los epistemológicos (sociológicos y psicológicos, críticos y científico sociales, empíricos e interpretativos), así como los campos académico y profesional (Reese, 2001; 2007; 2018). En esta capacidad de conexión radica para Reese (2007) el mayor poder del framing, en tanto que supone una herramienta con la capacidad de unir perspectivas disciplinares distintas en líneas comunes de investigación, a pesar de que desde cada una de ellas se realicen definiciones y operacionalizaciones diferentes de los conceptos centrales de la teoría. Esta es una idea compartida por D’Angelo (2002; 2012; 2018a), para quien constituye un programa de investigación multiparadigmático, debido a los diferentes acercamientos disciplinares en que se basa y que lo toman como objeto de estudio.

En su trabajo, D’Angelo (2002; 2012) apunta que al hablar del framing no nos encontramos ante una teoría, sino más bien ante un programa de investigación amplio, debido a que su estudio no implica, como ocurre en otras teorías, el análisis de una fase del proceso comunicativo en particular, sino su revisión en conjunto. Es más bien una metateoría que abarca distintos paradigmas de la comunicación, y en la que se estudian los procesos del framing, lo que implica tanto identificar las unidades temáticas llamadas frames, como evaluar las condiciones que permiten la activación de estos encuadres, así como analizar la manera en que los encuadres noticiosos interactúan con el conocimiento de la audiencia y, finalmente, determinar cómo éstos moldean procesos sociales como la opinión pública (p. 873). En este sentido, retoma el planteamiento original de Entman (1993) quien ya en su estudio apuntaba que el framing constituye un fenómeno que atraviesa todo el proceso informativo, algo ampliamente secundado por los diferentes autores de la disciplina (Carragee; Roefs, 2004; De-Vreese, 2003; 2005; Matthes, 2012; Reese, 2001; Scheufele, 2000).

Para Entman (1993), el proceso del framing se hace presente en cuatro localizaciones:

- en los comunicadores, que hacen juicios para decidir qué informar guiados por frames que organizan su sistema de creencias;

- en los textos que los contienen para el tratamiento de la información;

- en el público, puesto que los frames guían el pensamiento del público y, finalmente;

- en la cultura social, en cuanto que se crea un conjunto de frames exhibidos en el discurso y pensados por la mayoría de las personas dentro de un determinado grupo social.

En este sentido, constituye un proceso que implica la creación, selección y establecimiento de ciertos encuadres noticiosos (Matthes, 2012), bien dentro de los mensajes, bien en la mente de la audiencia a partir de diferentes esquemas mentales. Un planteamiento similar al del Carragee y Roefs (2004), para quienes el framing engloba 
"cómo los encuadres son patrocinados por los actores políticos, cómo los periodistas utilizan encuadres en la construcción de noticias, cómo estas noticias articulan frames y cómo los miembros de la audiencia los interpretan" (p. 215).
El proceso del framing se hace presente en cuatro localizaciones: en los comunicadores, los textos, el público y la cultura social

Las relaciones entre los frames presentes en estas locaciones contribuyen a establecer una serie de flujos que determinan los subprocesos del framing:

- el flujo de construcción de los encuadres,

- el flujo de definición de los frames, y el

- flujo de efectos de los encuadres (D’Angelo, 2002; 2019).

Tratando de dar lógica a este proceso de relaciones diferenciadas entre frames, así como de dotar de una estructura a su análisis, se han propuesto varios modelos que plantean un proceso integrado del framing (De-Vreese, 2003; 2012; Matthes, 2012; Scheufele, 1999) que en términos generales concluyen que su estudio implica el desarrollo de un proyecto de investigación amplio. Es el caso del modelo propuesto por Scheufele (1999; 2000), quien plantea el examen de los encuadres noticiosos tomando en consideración las diferentes dimensiones que se generan dentro del proceso, así como las relaciones entre los niveles del mismo.

Para el autor la primera relación a analizar es la que se establece entre el nivel macroscópico y el microscópico (between-level dimension). Mientras que en el nivel macroscópico están enmarcados los encuadres de los medios de comunicación (media frames), en el nivel microscópico se sitúan los encuadres del público (audience frames). Por otra parte, Scheufele (2000) esboza un análisis dentro de cada nivel (within-level dimension), donde los encuadres de los medios y del público pueden jugar los roles de variable independiente o dependiente en función de la etapa del proceso en el que estén actuando. Al respecto, el autor señala hasta tres etapas donde pueden relacionarse los encuadres: la creación de los encuadres (frame building), el establecimiento de los encuadres (frame setting) y los resultados o consecuencias cognitivas del proceso (consequences) donde se analizan sus efectos (Scheufele, 2006).

Por su parte, De-Vreese $(2003 ; 2005)$ recuerda la necesidad de estudiar el framing desde un proyecto de investigación integrado, donde se analice tanto la construcción del frame, como el frame en sí mismo y sus efectos en la audiencia, puesto que abarca todos los ámbitos del proceso de la comunicación. En particular, el autor establece un "modelo de framing como proceso integrado" ( De-Vreese, 2005) focalizado en el estudio de las tres etapas que principalmente rigen este proceso: la construcción del encuadre en las salas de prensa (framing in the newsroom) que en cierta medida alude al proceso de construcción del encuadre, la presencia del encuadre en las noticias (framing in the news), que alude al establecimiento de los frames, y el efecto que el tratamiento de la realidad a través de encuadres tiene en las audiencias (framing effects) donde se estudian las consecuencias del proceso a nivel individual. De esta manera, se establecen las tres áreas donde tradicionalmente se han desarrollo los estudios enmarcados en esta teoría: frame building, frame setting y framing effects.

A pesar de la necesidad de contar con acercamientos integrados de investigación del framing, el propio De-Vreese (2012) reconoce que suelen dominar los estudios a pequeña escala que se enfocan en partes del modelo por la complicación que conlleva desarrollar el estudio en el conjunto de todas las etapas del proceso.

Una excepción es el trabajo de De-Vreese (2003) acerca de los procesos de integración europea. Por una parte, el autor analizó el proceso de construcción de los frames a partir de entrevistas con periodistas y editores, posteriormente analizó el tratamiento utilizado por las televisoras para enfocar las elecciones europeas y, finalmente, determinó el efecto de los encuadres sobre las actitudes hacia la integración europea entre la audiencia. 0 también el proyecto de investigación liderado por Matthes (2012) que derivó en un número especial en la revista American behavioral scientist tomando como caso de estudio un referéndum suizo acerca de un proceso de naturalización de inmigrantes en el país. A lo largo de los artículos se puede tener una visión amplia de la complejidad que implica el proceso de estudio del framing.

\section{Construcción del encuadre (frame building)}

Un primer proceso de estudio dentro del proceso del framing es el que se centra en la elaboración de los encuadres, a partir del análisis de los factores que influyen en medios y periodistas a la hora de seleccionar la información y dotar a las noticias de un enfoque, o de la idea organizadora central mencionada por Tankard (2001) en su definición de frame. Este proceso analiza los factores que determinan la creación de los frames, los cuales determinarán en gran medida la calidad estructural de los encuadres (De-Vreese, 2003; 2005) al dotar al mensaje de una narrativa particular. Al respecto, se ha señala que el proceso de elaboración de los encuadres depende principalmente de dos factores (Scheufele, 2000):

- los internos que impactan en la forma en la que se encuadran los asuntos, como pueden ser las rutinas, los valores noticia, la ideología de los periodistas o editores, etc., y

- los factores externos a la organización, tales como la relación entre medios y élites o la posible influencia de las organizaciones sociales en las agendas mediáticas. 
Dentro de esta línea de investigación se ha considerado el trabajo interno de las redacciones como una de las claves para entender la formación de los encuadres pues, como recuerda Scheufele (2006), éstos

"no son idiosincrásicos, sino que son establecidos a través del discurso o debate que se suscita en las salas de prensa" (p. 67).

Es decir, existe un nivel individual donde actúan los esquemas o encuadres del propio periodista (journalist frames), definidos como los

"conjuntos cognitivos de esquemas relativos a los diferentes aspectos de la realidad" (Scheufele, 2006, p. 78),

que son utilizados para elaborar las informaciones que siempre serán consistentes con esos mismos puntos de vista. Pero, junto a ese nivel, también existe otro donde trabajan los encuadres de las redacciones (newsroom frames) que influyen a los encuadres del periodista (Entman et al., 2009). Es decir, el trabajo periodístico no se puede entender como individual, sino que más bien está influido por el debate interno de las redacciones, a través de la co-orientación entre periodistas y las rutinas establecidas dentro del medio en el que laboran, las que finalmente influyen la elección de ciertos encuadres y no de otros (Scheufele, 2006).

A pesar de la importancia que tiene comprender este proceso, habitualmente los estudios sobre framing han olvidado esta fase, centrándose más bien en la detección y análisis de los encuadres en los mensajes, así como de sus efectos sobre el público (Borah, 2011; Carragee; Roefs, 2004; Valera-Ordaz, 2016). A pesar de ello, existe una aceptable bibliografía dentro de esta línea de investigación que se ha centrado en los dos factores que Scheufele (2000) plantea como influyentes dentro del proceso. En este sentido, algunos trabajos han puesto su énfasis en el estudio de las reglas, normas periodísticas y valores noticiosos que determinan la utilización de ciertos encuadres para elaborar la información, en tanto que el framing ayuda a simplificar el trabajo de creación de la noticia (Dimitrova; Kostadinova, 2013; Scheufele, 2006; Rodelo; Muñiz, 2019). Es el caso del estudio de De-Vreese (2003), donde a través de entrevistas en profundidad analizó las estrategias que llevan a los periodistas determinar qué asuntos incluir y con qué encuadres elaborar la información. Este tipo de acercamientos cualitativos es el ideal para esta clase de estudios, pues permite inmiscuirse para conocer la práctica periodística a la hora de crear encuadres.

Junto a ello, también se han estudiado los factores explicativos ubicados en un nivel sistémico, es decir, tanto en el sistema político como en el sistema de medios (Dimitrova; Kostadinova, 2013), determinando las relaciones existentes entre ellos en la labor de creación de los encuadres. Dentro de este ámbito es importante el análisis de la influencia ejercida por los actores del sistema político -entendido de manera amplia al poder englobar también a actores como, entre otros, empresarios o grupos de presión- al patrocinar ciertos encuadres (advocacy frames) para presentar su visión particular de la realidad (Carragee; Roefs, 2004; De-Vreese, 2012). Dentro de esta línea es

A pesar de la importancia que tiene comprender el proceso de construcción del encuadre, los estudios habitualmente lo han olvidado

interesante el estudio sobre las relaciones de influencia entre los encuadres presentes en los subsidios informativos (media input) de los gobernantes y los usados para elaborar las noticias (Rodelo; Muñiz, 2019). Para ello, se trabaja con análisis de contenido cuantitativos que permiten analizar tanto el framing presente en las noticias, como en las notas de prensa, conferencias, entrevistas o declaraciones públicas de los actores políticos, relacionando la presencia de los encuadres en cada ámbito mediante técnicas estadísticas, como las correlaciones desfasadas en el tiempo.

\section{Estudio de los encuadres en las noticias (news framing)}

Una de las principales preocupaciones de los investigadores en comunicación centrados en el estudio de la teoría del framing ha sido la identificación de los tipos de encuadres presentes en los contenidos informativos de los medios. No en vano, los frames constituyen el concepto central dentro de la teoría, siendo a su vez la variable principal dentro del estudio del proceso de construcción del mensaje y de los efectos de éstos en las opiniones de la audiencia (De-Vreese, 2012; Matthes, 2012). En este contexto, el estudio se ha centrado en el análisis de la manera en que los encuadres se manifiestan en las noticias (framing in the news), lo que conlleva tanto determinar cómo utilizan los periodistas los encuadres para construir las noticias, así como la manera en que dentro de estas noticias se articulan diferentes frames para estructurar la narrativa (Carragee; Roefs, 2004; Rodelo; Muñiz, 2017). Esto pone de manifiesto la especial vinculación que el framing tiene con la práctica periodística, lo que ha llevado a D’Angelo y Shaw (2018) a plantear que, al hablar de su estudio, en gran medida se está haciendo referencia al análisis del periodismo.

Dentro de la labor de transmisión y traducción de los acontecimientos que atañe a los medios, una herramienta crucial con la que cuentan los periodistas es el framing, gracias al cual pueden ofrecer un tratamiento informativo determinado en sus noticias respecto de los asuntos relevantes a nivel social (De-Vreese, 2003; 2005). Algo que se puede realizar mediante un framing textual y/o uno visual (Messaris; Abraham, 2001). En este sentido, los medios realizan un proceso de traducción de la información, a través del uso de encuadres o enfoques con los que ofrecen un tratamiento informativo particular de la realidad (D’Angelo, 2002; Entman, 1993; Matthes, 2012). La investigación ha demostrado que la cobertura mediática de la realidad se caracteriza por la utilización de abundantes y diversos encuadres para presentar los asuntos que los investigadores tratan de identificar en sus análisis (De-Vreese, 2005; Brugman et al., 2017), lo que 
ha llevado a que ésta sea una de las líneas más fecundas de estudio, tanto a nivel internacional, como en el entorno hispanoamericano, donde se ha criticado incluso el excesivo "sesgo mediocéntrico" (Valera-Ordaz, 2016).

La investigación en el campo ha planteado normalmente la existencia de dos tipos de encuadres que pueden detectarse en los contenidos informativos (Ardèvol-Abreu, 2015; Brugman; Burgers, 2018; De-Vreese, 2005): los genéricos (generic news frames) y los de asunto específico (issue-specific news frames), en adelante específicos. Los encuadres genéricos pueden ser detectados en cualquier tipo de mensaje, y, por tanto, son aplicables al estudio de los mensajes independientemente de la temática abordada en ellos. Para D’Angelo (2018b) estos encuadres remiten a la cobertura que los periodistas ofrecen a la información recibida desde los encuadres de promoción. Por su parte, los encuadres específicos permiten describir las diferentes aristas de un tema en particular. En este caso, D’Angelo (2018b) señala que vienen a constituir la contraparte de los encuadres de promoción, ayudando a dar cobertura de los asuntos desde diferentes ángulos al señalado como prioritario por las fuentes informativas. Si bien ambos están presentes dentro de la práctica periodística habitual, el debate acerca de los pros y contras de su uso en el terreno investigador se mantiene (Brugman et al., 2017; Lecheler; De-Vreese, 2016).

En cuanto a los encuadres genéricos, su mayor ventaja radica en su aplicabilidad al estudio de cualquier temática o evento, al asumirse su posible presencia indistintamente del contenido informativo que se esté analizando. Sin embargo, su desventaja se encuentra en su debilidad para profundizar en el estudio de un tema o asunto concreto, al no poder ofrecer información detallada del tratamiento dado al asunto (De-Vreese, 2005). Hasta la fecha, son varios los listados de encuadres genéricos planteados por los investigadores para el estudio de los frames noticiosos. Una de estas tipologías es la aportada por Semetko y Valkenburg (2000), constituida por cinco encuadres genéricos: "atribución de responsabilidad", "conflicto", "interés humano", "consecuencias económicas" y "moralidad", la cual ha sido utilizada ampliamente (De-Vreese, 2003; 2005). Otros campos donde se han esbozado listados de encuadres genéricos son la política, donde se visualizan los encuadres de "asunto" y de "juego estratégico" (Cappella; Jamieson, 1997; Dimitrova; Kostadinova, 2013) y el estudio de las rutinas, normas o valores que son inherentes a los periodistas, donde se plantea el encuadre "temático" frente al "episódico" (De-Vreese, 2005).

Junto a este enfoque de framing genérico se asume que en las noticias también están presentes ciertos encuadres específicos que permiten presentar las diferentes aristas que atañen a un asunto en particular. Es precisamente este aspecto el que convierte a los encuadres específicos en un apoyo esencial a la investigación, de-

bido a que con ellos se puede profundizar en el estudio de temáticas o eventos que emergen en la agenda informativa habitualmente (De-Vreese, 2005). Como contrapartida, su especificidad presenta un problema de cara a la búsqueda de conclusiones generalizables y comparables para distintos temas o asuntos (Brugman; Burgers, 2018; De-Vreese, 2005). Pero, más allá del tratamiento ofrecido en los medios a los asuntos, estos encuadres también permiten estudiar cómo las personas construyen su comprensión acerca de los asuntos, a partir de la información recibida en los mensajes (Brugman; Burgers, 2018). En este sentido, mientras que en muchos estudios sobre contenidos se han empleado encuadres genéricos (De-Vreese, 2012), en buena parte de los estudios experimentales se han utilizado encuadres específicos como estímulo (Brugman; Burgers, 2018; Brugman et al., 2017).

Pero, si bien el corpus de investigación empírica existente en torno al estudio de los encuadres en las noticias es vasto y riguroso, no se puede negar que en la práctica investigadora también existen trabajos en los que, dejándose llevar por usos, modas o tendencias, el uso del término framing es lo único que los vincula con este paradigma teórico (Reese, 2007). Esta moda ha llevado a no pocos autores a presentar como estudios de framing ciertos trabajos donde

"el uso que está detrás del término encuadre se encuentra en las antípodas de los parámetros que marca la investigación contemporánea” (Vicente-Mariño; López-Rabadán, 2009, p. 29).

Y es que, como recuerda De-Vreese (2005), el estudio riguroso de los encuadres dentro de los mensajes implica un proceso complejo debido a que los encuadres son conceptos que eluden la medición. Su estudio implica determinar en primer lugar qué es o qué se entiende por encuadre o frame, además de decidir qué aspectos hay que analizar para poder detectarlo y establecer el mejor procedimiento para su estudio (Matthes; Kohring, 2008).

Aquí radica uno de los problemas principales del estudio de los encuadres en las noticias: el establecimiento de definiciones operativas que neutralicen el impacto del investigador a la hora de determinar la presencia del encuadre (Matthes; Kohring, 2008) y que, a su vez, constituyan instrumentos válidos que hagan innecesario que cada investigador plantee instrumentos diferentes (Vicente-Mariño; López-Rabadán, 2009). Para ello se debe asumir que el encuadre es un concepto sofisticado, cuyo estudio va más allá de determinar si se presenta favorable o desfavorablemente cierto asunto en los medios (Tankard, 2001) o de la elaboración de listados de tópicos o asuntos que emergen de forma manifiesta a partir de análisis del contenido del mensaje (Reese, 2018). El encuadre remite, más bien, a

"constructos o variables latentes, no observables ni medibles directamente sino que emergen a partir de una serie de indicadores manifiestos" (Igartua; Muñiz; Cheng, 2005, p. 157). 
Es decir, los frames son estructuras latentes que deben ser identificados a partir del análisis de ciertos rasgos presentes en el mensaje, como pueden ser argumentos, actores o palabras clave, y que están presentes en el mensaje de forma no excluyente entre sí, es decir, unos encuadres pueden coexistir con otros de forma simultánea.

Esto implica la necesidad de desarrollar acercamientos metodológicos de análisis y medida más exigentes que permitan detectar estos constructos que configuran los encuadres dentro de las noticias (Reese, 2018). Y es que, a pesar de la popularidad que el framing ha alcanzado dentro de los estudios de la disciplina, esto no ha impedido que se presente una inconsistencia en torno al diseño metodológico para el análisis de los encuadres en las noticias (De-Vreese, 2005). De hecho, en la bibliografía se pueden encontrar diferentes acercamientos metodológicos para el estudio de los frames, aunque como ponen de manifiesto las revisiones realizadas en torno al corpus de trabajos empíricos en términos generales la técnica predominante en la mayoría de ellos ha sido el análisis de contenido, principalmente desde un acercamiento cuantitativo (Ardèvol-Abreu, 2015; Borah, 2011; De-Vreese, 2005; Saperas; Carrasco-Campos, 2015). Se observa, por tanto, un déficit de estudios cualitativos sobre framing, a pesar de que estas técnicas posibilitan profundizar en la comprensión del uso de ciertos encuadres en las noticias independientemente de que no hayan sido los más enfatizados en la información analizada, aunque siempre a costa de tener que trabajar con muestras pequeñas (Reese, 2001).

Tratando de poner claridad en la diversidad de acercamientos metodológicos seguidos para analizar el framing noticioso, Matthes y Kohring (2008) plantean que son cinco los acercamientos metodológicos que se han empleado para detectar encuadres.

- En primer lugar, los autores señalan el acercamiento hermenéutico, de corte cualitativo y donde normalmente se vinculan los frames con elementos culturales para poder detectarlos.

- También mencionan el acercamiento lingüístico, donde los encuadres son detectados a través del análisis de la selección, emplazamiento y estructura de las palabras y sentencias dentro del mensaje.

- En tercer lugar, señalan el acercamiento holístico manual, que implicaría hasta cierto punto un acercamiento mixto similar al planteado por Van-Gorp (2010), al necesitar primero de la detección cualitativa de los encuadres dentro del mensajes para posteriormente medir de forma cuantitativa su presencia en un corpus más amplio.

- Matthes y Kohring (2008) también señalan el acercamiento asistido por computadora, donde se analiza la coocurrencia de palabras clave dentro de los textos, lo que posibilita el estudio de amplios corpus de mensajes.

- Finalmente mencionan el acercamiento deductivo, donde en primer lugar se plantean teóricamente los frames y luego se mide su presencia en los textos.

Frente a esta clasificación amplia de técnicas para la detección de los encuadres, otros autores han reducido los acercamientos a dos: el inductivo y el deductivo (Ardèvol-Abreu, 2015; De-Vreese, 2003; 2005; Semetko; Valkenburg, 2000). Desde el acercamiento inductivo se trabaja realizando un análisis a fondo de los mensajes, con el fin de revelar los encuadres existentes a partir de las relaciones existentes entre sus elementos constitutivos. Por tanto, el aspecto crucial en este acercamiento será la determinación de los elementos que deben ser medidos para lograr que los encuadres latentes se hagan manifiestos a través del análisis de contenido del mensaje (Igartua et al., 2005). Por el contrario, desde el acercamiento deductivo se parte de una definición previa de ciertos encuadres que se espera que estén presentes en el mensaje, y que actuarán como variables analíticas para realizar el análisis de contenido (Ardèvol-Abreu, 2015; De-Vreese, 2005). Por tanto, la labor del investigador radica en determinar a priori, y atendiendo al objetivo de investigación, los encuadres que sean más oportunos de entre los planteados en los listados de encuadres genéricos o específicos.

A la vista de las características de ambos acercamientos se puede entender que la mayor complejidad entre ambos diseños se presenta para la realización de estudios de corte inductivo (Ardèvol-Abreu, 2015), en tanto que la definición operacional de los encuadres en los estudios deductivos ya está ofrecida en los trabajos previos que se tomen como referencia. Esta complejidad radica en el hecho de que el acercamiento inductivo implica un análisis a fondo de las historias narradas en las noticias con el fin de revelar los encuadres existentes. Para ello, se comenzará por definir preconcepciones definidas levemente en los mensajes, como puede ser un listado de palabras clave que se utilizarán para construir categorías amplias, excluyentes y exhaustivas (Igartua et al., 2005). Este procedimiento, aunque es más laborioso, logra unos resultados más satisfactorios para analizar el tratamiento informativo de la actualidad en los medios de comunicación a través de diferentes encuadres. Sin embargo, también plantea problemas, como el hecho de que los listados de encuadres obtenidos no pueden ser replicados en nuevas investigaciones de una forma tan sencilla como sí se puede hacer con los encuadres genéricos (De-Vreese, 2003; 2005).

Dentro del modelo inductivo se puede situar la propuesta metodológica de Matthes y Kohring (2008), que implica el desarrollo de un análisis multivariado mediante un análisis de conglomerados de los reactivos que describen el contenido de los mensajes. Para ello, los autores proponen utilizar como variables analíticas los elementos de los encuadres aportados en la definición del encuadre por Entman (1993). Esto es, analizar la presencia en el texto de reactivos que denoten la definición del problema abordado, determinando su naturaleza y los elementos que lo definen, la emisión 
de juicios o evaluaciones morales acerca de cómo fue definido el asunto, si en el mensaje se realiza un diagnóstico acerca de las causas del problema y, finalmente, si se presentan las posibles soluciones sugeridas para abordar el problema descrito (Rodelo; Muñiz, 2019). Sin embargo, este procedimiento ha sido cuestionado por De-Vreese (2012) ya que no siempre los elementos aparecen en las noticias con excepción de la definición del problema que constituye la

"característica más importante de un frame, la cual se puede capturar a través de palabras clave o argumentos" presentes en el mensaje (p. 367).

Ello remite al modelo propuesto por Miller y Riechert (2001), quienes parten de la idea planteada por Entman (1993) de que los encuadres mediáticos pueden ser detectados a través de la determinación de la

"presencia y ausencia de ciertas palabras clave" (p. 53).

Esta técnica de estudio, denominada frame mapping, implica establecer listados de palabras clave existentes en las noticias para posteriormente evaluar su presencia dentro del conjunto de unidades analizadas. A partir de esta estimación se realizan análisis multivariados para determinar su organización semántica (intensidad de las coocurrencias entre ellas) y descubrir las dimensiones subyacentes que se manifiestan en forma de encuadres noticiosos (Igartua et al., 2005). Considerando lo señalado por Cappella y Jamieson (1997), estas dimensiones sólo podrán ser definidas como frames si tienen características conceptual y lingüísticamente identificables, si se puede distinguir claramente de otros encuadres, si están validadas empíricamente y no son solo fruto de la reflexión del investigador y si su uso se ha observado dentro de la práctica periodística donde se realiza el estudio, debido a que es imposible que cuando los periodistas encuadran los acontecimientos en las noticias no dejen de verse influidos por el contexto cultural en el que se desempeñan (D’Angelo, 2018b; Van-Gorp, 2010).

\section{Estudio de los efectos de los encuadres (framing effects)}

Al describir el framing, D’Angelo (2019) señala que éste conlleva el intento permanente de los individuos de influir a otros a través de mensajes (p. 1), es decir, el efecto que el establecimiento de encuadres en los mensajes tiene sobre la audiencia que los consume. Este proceso de efectos encajaría tanto dentro de la fase del establecimiento de los encuadres (frame setting) planteada por De-Vreese $(2003 ; 2005)$ en su modelo, como dentro de las consecuencias cognitivas señaladas por Scheufele (2006). En este sentido, el estudio del efecto del tratamiento informativo (framing effect) implica abordar, por tanto, dos fenómenos: cómo se hacen manifiestos los encuadres noticiosos en los textos informativos para, en segundo lugar, analizar el proceso por el que los encuadres noticiosos influyen en la opinión pública a través de la generación de efectos sociocognitivos a nivel individual sobre la audiencia (Entman, 1993; Scheufele, 1999; 2000; Semetko; Valkenburg, 2000). Se trata en definitiva de un proceso donde los encuadres de los medios (media frames) actúan como variable independiente, mientras que los encuadres del público o de la audiencia (audience frames) lo hacen como variable dependiente (Scheufele, 1999; 2000).

Aunque en la práctica investigadora siguen dominando los estudios donde se evalúa la cobertura mediática y el tratamiento informativo dado a los asuntos en las noticias a través del uso de encuadres, poco a poco la teoría del encuadre se ha deslizado hacia el estudio de los efectos mediáticos. Así lo pone de manifiesto la revisión de Saperas y Carrasco-Campos (2015) en el Journal of communication, donde frente a un 30\% de artículos basados en análisis de contenido, detectaron un $22 \%$ con acercamiento experimental. Son numerosos los autores que han intentado determinar la influencia que los encuadres tienen sobre el público (Carragee; Roefs, 2004; De-Vreese, 2012). Por ejemplo, y tan solo en el campo de la comunicación política, recientemente Brugman et al. (2017) y Brugman y Burgers (2018) localizaron respectivamente más de 300 estudios experimentales, los cuales además se insertaban dentro del corpus de investigación de disciplinas variadas como la ciencia política, la comunicación o la psicología. Sin embargo, en el terreno hispanoamericano estos trabajos siguen siendo residuales, como lo manifiesta el escaso 3,8\% de investigaciones experimentales detectadas en su revisión por Piñeiro-Naval y Mangana (2019).

El cada vez más extenso número de estudios sobre los posibles efectos de los encuadres noticiosos en la audiencia hace necesario organizar y sistematizar la tipología de estos efectos. Sin embargo, y al igual que ocurriera con la conceptualización del framing y el frame, emergen en la bibliografía propuestas que pretenden explicar el modo en que los encuadres operan y sus resultados sobre el público. Habitualmente se ha entendido que este efecto constituye un proceso cognitivo, por el que los medios ayudan al establecimiento de los encuadres en el pensamiento de la audiencia (De-Vreese, 2003; Druckman, 2001). Es decir, se genera un efecto de canalización cognitiva que conlleva la traslación del encuadre desde el mensaje a la mente del público, que una vez instalado allí será utilizado como una herramienta para pensar sobre el asunto y construir opiniones y juicios (Druckman, 2001; Entman et al., 2009; Matthes, 2012), lo que lleva a D’Angelo (2018b) a señalar que los frames gobiernan y restringen lo que las personas dicen y hacen. Sin embargo, este efecto no se agota en el terreno cognitivo, pudiendo conllevar un proceso de efecto a nivel actitudinal y conativo (De-Vreese, 2005; Scheufele, 2004, 2006). 
Se asume, por tanto, que a partir del impacto cognitivo los encuadres tienen la capacidad de producir cambios en los juicios, actitudes, opiniones, emociones y/o decisiones de los individuos. Tomando como referencia esta lógica, Scheufele (2004) plantea que existen cuatro tipos de efectos de los frames, explicados a través del "modelo de los dos escalones" (two-step-model).

- En primer lugar se pueden producir tres efectos a nivel cognitivo derivados de la convergencia entre encuadres y esquemas en la mente de las personas. Allí se puede producir bien una activación de los esquemas ya existentes, una transformación de estos esquemas o incluso la formación de nuevos esquemas acerca de los asuntos informados.

- En segundo lugar se producirá un efecto actitudinal, el cuarto dentro del modelo propuesto por el autor, manifestado a través de cambios en los juicios, actitudes, opiniones, emociones y/o decisiones de los individuos como resultado de la activación o la alteración previa de los esquemas.

Por su parte, De-Vreese (2003) apunta la existencia de tres tipos de efectos del framing: a) efectos de tipo cognitivo sobre el procesamiento de la información, b) efectos de tipo afectivo sobre las opiniones y las actitudes y c) efectos sobre el comportamiento.

En su mayoría, estos estudios sobre efectos han sido desarrollados desde diseños de corte experimental que buscan el estudio de la causalidad (De-Vreese, 2012), donde primero se manipula la presencia de los encuadres el mensaje que sirve de estímulo, para luego determinar su influencia sobre el público (Carragee; Roefs, 2004). Sin embargo, y a pesar de la importante evidencia que esta línea de investigación centrada en diseños experimentales ha generado, son varias las dudas que se han planteado acerca de los posibles problemas existentes dentro del método que necesitarían ser corregidos (De-Vreese, 2012; Matthes, 2008; Scheufele, 2004). Por ejemplo, se ha cuestionado la posible traslación de los resultados de los estudios en laboratorio a entornos reales de consumo mediático de los ciudadanos. Es decir, se pone en duda si la baja validez externa de estos diseños permite extrapolar los efectos causales encontrados a la realidad social (Shehata, 2014), debido a que en gran medida los experimentos fuerzan una exposición artificial a contenidos en un contexto no realista, que no tiene por qué representar la relación que realmente tiene la audiencia con los medios (De-Vreese, 2012).

La realización de experimentos acerca del efecto del framing habitualmente implica la selección de un encuadre específico sobre un asunto que fungirá como estímulo en el diseño experimental, centrándose para ello

"en un aspecto concreto de la cobertura informativa de los medios" (Price; Nir; Capella, 2005, p. 181).

Este proceso lleva a que en muchas ocasiones el contenido informativo utilizado no sea real, sino más bien manipulado experimentalmente por el propio investigador en el laboratorio (Scheufele, 1999; 2000), lo que resta realismo al estudio (De-Vreese, 2012). Por ello, Scheufele (1999; 2000) plantea como más adecuado la realización de estudios en dos niveles: en el primero se determinan los encuadres noticiosos mediante análisis de contenido de las noticias que dan cobertura al asunto investigado (Scheufele, 2004), mientras que en el segundo nivel se utilizan los encuadres detectados en las noticias para preparar el material que servirá de estímulo dentro del experimento. Es decir, que en el diseño de los estudios sobre el framing se combinen análisis de contenido (para estudiar los encuadres mediáticos) y experimentos (para determinar su efecto sobre el público) (Price et al., 2005).

Por otra parte, también se ha cuestionado que en muchos de los estudios sobre los efectos del framing los encuadres que son utilizados como estímulo sean presentados a los participantes en una única ocasión, pretendiendo observar y medir a posteriori los efectos producidos por esa exposición aislada (Scheufele, 2004). Al respecto, De-Vreese (2012) apunta que uno de los retos dentro del estudio de los efectos es revisar precisamente la duración en el tiempo del efecto de los encuadres, algo poco abordado hasta la fecha (Lecheler; De-Vreese, 2016). Por otra parte, el autor también señala como importante y necesaria la revisión de los efectos que se producen tras la exposición repetida a un mismo encuadre, o bien la exposición simultánea a encuadres contradictorios, lo que podría incrementar la validez externa de los estudios al acercarse más a una exposición mediática de la audiencia más ajustada a la realidad. Esta es una importante limitación para estos estudios, tomando en consideración la cada vez mayor exigencia de realismo que se reclama a los estudios sobre efectos mediáticos (De-Vreese, 2005).

Ante esta limitación se ha planteado la necesidad de realizar estudios con más realismo y validez externa para acercarse en mayor medida a la comprensión del efecto, es decir, utilizar diseños que permitan aumentar la generalización de los estudios sobre efecto framing (De-Vreese, 2012; Matthes, 2008; Shehata, 2014). Sin embargo, esto no debe necesariamente implicar un menoscabo de la sofisticación que históricamente han tenido los diseños experimentales en cuanto a la medición con precisión de las relaciones causales (De-Vreese, 2012). Desde esta corriente empírica se ha propuesto transitar hacia el denominado "realismo experimental", que busca moverse más allá de los estudios en laboratorio para explorar los efectos del framing en el mundo real. Para ello se propone trabajar con mediciones más realistas del consumo de contenidos de los medios, frente a una exposición a encuadres manipulados experimentalmente. Esto se consigue vinculando mediciones de la opinión pública, registrada a partir de encuestas panel, con datos sobre la pre- 
sencia de los encuadres en la cobertura mediática de la realidad, obtenidos a partir de análisis de contenido de noticias (De-Vreese, 2012; Matthes, 2008).

\section{Algunas reflexiones finales}

Lo expuesto en los puntos anteriores da cuenta de la riqueza que el framing como proyecto de investigación representa para los investigadores de la comunicación, al dotarlos de herramientas para analizar de una forma amplia todo el proceso que implica la comunicación, pero también de forma particular cada una de las etapas por las que transita el mensaje, así como de los encuadres que se han utilizado para su elaboración o los que se establecen en la audiencia que los recibe. A pesar de ello, cabe realizar algunas reflexiones acerca de su aplicación actual en el contexto hispanoamericano donde, independientemente del creciente corpus de investigación con el que se cuenta, el framing aún sigue siendo una teoría emergente o en "fase embrionaria" como señalara Ardèvol-Abreu (2015) para España. Más allá del debate acerca de su naturaleza como paradigma fracturado o como espacio de conexión interdisciplinar entre diferentes visiones sobre el proceso comunicativo (D’Angelo, 2002; Entman, 1993; Reese, 2018), un importante problema que atañe a la investigación sobre framing radica en la facilidad con la que en ocasiones se engloban dentro la teoría trabajos por el simple hecho de hacer uso de conceptos como framing o frames.

En la práctica es habitual encontrar trabajos que plantean más bien análisis de temas o asuntos presentes en los mensajes, en lugar de la realización de un efectivo análisis de encuadres (frame analysis). Y es que, como se mencionó en un punto anterior, el estudio del encuadre es complejo, al ser un concepto que se manifiesta en los mensajes de forma latente, lo que requiere de análisis sofisticados para su detección y medición. La complejidad de los estudios realizados, desde diferentes propuestas metodológicas, para detectar encuadres a partir del acercamiento inductivo son buena prueba del problema al que se enfrenta el investigador a la hora de realizar esta investigación. Ello lleva a que en ocasiones se utilicen acercamientos deductivos que ayudan en el desarrollo del estudio de los frames, pero que ofrecen menor riqueza que los inductivos para desentrañar la labor periodística para transmitir la realidad social. Aunque esto no resta mérito a los trabajos deductivos, sí supone un reto para su realización en la medida en que se debe buscar precisión en la medición de los encuadres a través de la utilización de instrumentos ya creados y validados, más allá de elaborar nuevas operacionalizaciones diferentes a las ya existentes para medir los mismos encuadres.

En todo caso, la aplicación de escalas de encuadres existentes y la interpretación de los resultados obtenidos en los estudios sobre framing siempre debe realizarse desde la óptica del contexto cultural donde se realiza el ejercicio de análisis. $Y$ es que, aunque el proceso del framing es factible de producirse en cualquier sistema mediático, es muy posible que ciertos encuadres no presenten una consistencia similar en unos contextos frente a otros, debido a las diferencias culturales que existen entre ellos y que dotan de características propias a los encuadres. Un ejemplo concreto es la escala de encuadres genéricos de Semetko y Valkenburg (2000), una de las más utilizadas para analizar temáticas variadas. A pesar de la clara diferencia que las autoras establecen entre los encuadres del listado, en algunos estudios llevados a cabo en América Latina encuadres como los de "atribución de responsabilidad" o "conflicto" tiendan a entrelazarse, o el de "moralidad" en su operacionalización original muestra una presencia anecdótica, cuando no nula, en las noticias. Esto pone de manifiesto la necesidad de analizar con cautela los resultados, entendiendo que la praxis periodística puede estar marcada por factores contextuales y culturales que impactan en el tratamiento realizado.

Se pone de manifiesto, por tanto, la necesidad de mejorar las estrategias metodológicas para el estudio de los encuadres transmitidos en los mensajes, tanto específicos como genéricos, y desde acercamientos inductivos o deductivos. Dicho esto cabe recordar que el framing, en tanto que programa o proyecto de investigación, abarca todas las fases del proceso comunicativo y que, por tanto, su estudio no se agota en la detección y medición del uso de encuadres dentro del mensaje. Los diferentes estudios bibliométricos realizados no llevan sino a confirmar ese "sesgo mediocéntrico" que Valera-Ordaz (2016) apunta a la hora de hablar sobre la práctica investigadora en España, algo extrapolable nuevamente a Latinoamérica (Piñeiro-Naval; Morais, 2020). Esto pone de manifiesto la necesidad de incrementar los estudios sobre la construcción del encuadre (frame building), así como acerca de los efectos en la audiencia del uso de esos encuadres (framing effects), dos campos de trabajo prácticamente olvidados en la región, a pesar de la riqueza que estos estudios pueden suponer para comprender las rutinas y prácticas periodísticas, así como la conformación de la opinión pública.

Si bien el incremento de estudios sobre framing es constante y la evidencia empírica se acumula a nivel internacional, así como por supuesto en el contexto hispanoamericano, esto no ha ido unido a la creación de grupos o equipos de trabajo especializados que generen escuela. Al respecto, hay que convenir con Vicente-Mariño y López-Rabadán (2009) cuando señalan esta debilidad para España, lo que también es extrapolable al caso latinoamericano (Piñeiro-Naval; Morais, 2020). Esto ha llevado a que buena parte de la evidencia empírica derive de esfuerzos individuales de investigadores que trabajan con sus propios recursos y de manera aislada. Esta realidad muy presente en España (Vicente-Mariño; López-Rabadán, 2009), se acentúa considerablemente en los países latinoamericanos, donde es casi imposible encontrar grupos de investigación que focalicen sus esfuerzos en el desarrollo de estudios sobre framing. Una realidad que puede ser paliada con el establecimiento de redes de trabajo y colaboración entre investigadores

Se pone de manifiesto la necesidad de mejorar las estrategias metodológicas para el estudio de los encuadres transmitidos en los mensajes 
de la región, pues dentro de ellas se pueden encontrar un apoyo que ayude a reducir la complejidad que conlleva el estudio del encuadre, favoreciendo además el desarrollo de estudios transculturales que aún son escasos dentro de la bibliografía sobre framing.

\section{Referencias}

Ardèvol-Abreu, Alberto (2015). “Framing o teoría del encuadre en comunicación. Orígenes, desarrollo y panorama actual en España”. Revista latina de comunicación social, n. 70, pp. 423-450.

https://doi.org/10.4185/RLCS-2015-1053

Borah, Porismita (2011). "Conceptual issues in framing theory: A systematic examination of a decade's literature". Journal of communication, v. 61, n. 2, pp. 246-263.

https://doi.org/10.1111/j.1460-2466.2011.01539.x

Brugman, Britta C.; Burgers, Christian (2018). "Political framing across disciplines: Evidence from $21^{\text {st }}$-century experiments". Research and politics, v. 5, n. 2.

https://doi.org/10.1177/2053168018783370

Brugman, Britta C.; Burgers, Christian; Steen, Gerard J. (2017). "Recategorizing political frames: a systematic review of metaphorical framing in experiments on political communication". Annals of the International Communication Association, v. 41, n. 2, pp. 181-197.

https://doi.org/10.1080/23808985.2017.1312481

Bryant, Jennings; Miron, Dorina (2004). "Theory and research in mass communication". Journal of communication, v. 54, n. 4, pp. 662-704.

https://doi.org/10.1111/j.1460-2466.2004.tb02650.x

Cacciatore, Michael A.; Scheufele, Dietram A.; lyengar, Shanto (2016). "The end of framing as we know it... and the future of media effects". Mass communication and society, v. 19, n. 1, pp. 7-23.

https://doi.org/10.1080/15205436.2015.1068811

Cappella, Joseph N.; Jamieson, Kathleen-Hall (1997). Spiral of cynicism: The press and the public good. USA: Oxford University Press. ISBN: 9780195090642

Carragee, Kevin M.; Roefs, Wim (2004). "The neglect of power in recent framing research". Journal of communication, v. 54, n. 2, pp. 214-233.

https://doi.org/10.1111/j.1460-2466.2004.tb02625.x

Chong, Dennis; Druckman, James N. (2007). "Framing theory". Annual review of political science, v. 10, pp. 103-126. https://doi.org/10.1146/annurev.polisci.10.072805.103054

D’Angelo, Paul (2002). “News framing as a multiparadigmatic research program: A response to Entman”. Journal of communication, v. 52, n. 4, pp. 870-888.

https://doi.org/10.1111/j.1460-2466.2002.tb02578.x

D’Angelo, Paul (2012). "Studying framing in political communication with an integrative approach". American behavioral scientist, v. 56, n. 3, pp. 353-364.

https://doi.org/10.1177/0002764211426332

D’Angelo, Paul (2018a). "Preface”. In: D’Angelo, Paul. Doing news framing analysis II. Empirical and theoretical perspectives. USA: Routledge, pp. 17-21. ISBN: 9781315642239

https://doi.org/10.4324/9781315642239

D’Angelo, Paul (2018b). "Prologue: A typology of frames in news framing analysis". In: D’Angelo, Paul. Doing news framing analysis II. Empirical and theoretical perspectives. USA: Routledge, pp. 23-40. ISBN: 9781315642239

https://doi.org/10.4324/9781315642239

D’Angelo, Paul (2019). "Framing theory and journalism”. In: Vos, Tim P.; Hanusch, Folker. The international encyclopedia of journalism studies, pp. 1-10. USA: Wiley Online Library. ISBN: 9781118841679.

https://doi.org/10.1002/9781118841570.iejs0021

D’Angelo, Paul; Shaw, Donna (2018). “Journalism as framing”. In: Vos, Tim. Handbook of communication science: Journalism, v. 19, pp. 205-233. Germany: M. de Gruyter.

https://doi.org/10.1515/9781501500084

De-Vreese, Claes H. (2003). Framing Europe: Television news and European integration. The Netherlands: Aksant Academic Publishers. ISBN: 9789055892341

De-Vreese, Claes H. (2005). “News framing: Theory and typology”. Information design journal, v. 13, n. 1, pp. 51-62.

https://doi.org/10.1075/idjdd.13.1.06vre 
De-Vreese, Claes H. (2012). “New avenues for framing research”. American behavioral scientist, v. 56, n. 3, pp. 365-375. https://doi.org/10.1177/0002764211426331

Dimitrova, Daniela V.; Kostadinova, Petia (2013). "Identifying antecedents of the strategic game frame". Journalism \& mass communication quarterly, v. 90, n. 1, pp. 75-88.

https://doi.org/10.1177/1077699012468739

Druckman, James N. (2001). "The implications of framing effects for citizen competence”. Political behavior, v. 23, n. 3, pp. 225-256.

https://doi.org/10.1023/A:1015006907312

Entman, Robert M. (1993). "Framing: Toward clarification of a fractured paradigm". Journal of communication, v. 43, n. 4, pp. 51-58.

https://doi.org/10.1111/j.1460-2466.1993.tb01304.x

Entman, Robert M.; Matthes, Jörg; Pellicano, Lynn (2009). "Nature, sources, and effects of news framing". In: Wahl-Jorgensen, Karin; Hanitzsch, Thomas. The handbook of journalism studies, pp. 175-190. USA: Routledge. ISBN: 9781 315167497

https://doi.org/10.4324/9781315167497

Igartua, Juan-José; Muñiz, Carlos; Cheng, Lifen (2005). “La inmigración en la prensa española. Aportaciones empíricas y metodológicas desde la teoría del encuadre noticioso". Migraciones, n. 17, pp. 143-181.

https://revistas.comillas.edu/index.php/revistamigraciones/article/view/4220

Kahneman, Daniel; Tversky, Amos (1984). “Choices, values, and frames”. American psychologist, v. 39, n. 4, pp. $341-350$. https://doi.org/10.1037/0003-066X.39.4.341

Lecheler, Sophie; De-Vreese, Claes H. (2016). "How long do news framing effects last? A systematic review of longitudinal studies". Annals of the International Communication Association, v. 40, n. 1, pp. 3-30.

https://doi.org/10.1080/23808985.2015.11735254

Matthes, Jörg (2008). "Media frames and public opinion: Exploring the boundaries of framing effects in a two-wave panel study". Studies in communication sciences, v. 8, n. 2, pp. 101-128.

https://doi.org/10.5167/uzh-14296

Matthes, Jörg (2009). "What's in a frame? A content analysis of media framing studies in the world's leading communication journals, 1990-2005". Journalism and mass communication quarterly, v. 86, n. 2, pp. 349-367.

https://doi.org/10.1177/107769900908600206

Matthes, Jörg (2012). “Framing politics: An integrative approach”. American behavioral scientist, v. 56, n. 3, pp. $247-259$. https://doi.org/10.1177/0002764211426324

Matthes, Jörg; Kohring, Matthias (2008). "The content analysis of media frames: Toward improving reliability and validity". Journal of communication, v. 58, n. 2, pp. 258-279.

https://doi.org/10.1111/j.1460-2466.2008.00384.x

Messaris, Paul; Abraham, Linus (2001). "The role of images in framing news stories”. In: Reese, Stephen D.; Gandy, Oscar H.; Grant, August E. Framing public life: perspectives on media and our understanding of the social world, pp. 215-226. USA: Lawrence Erlbaum Associates. ISBN: 9780805849264

Miller, Mark M.; Riechert, Bonnie P. (2001). "The spiral of opportunity and frame resonance. Mapping the issue cycle in news and public discourse". In: Reese, Stephen D.; Gandy, Oscar H.; Grant, August E. Framing public life: perspectives on media and our understanding of the social world, pp. 107-121. USA: Lawrence Erlbaum Associates. ISBN: 9780 805849264

Piñeiro-Naval, Valeriano; Mangana, Rafael (2019). "La presencia del framing en los artículos publicados en revistas hispanoamericanas de comunicación indexadas en Scopus". Palabra clave, v. 22, n. 1, pp. 117-142.

https://doi.org/10.5294/pacla.2019.22.1.6

Piñeiro-Naval, Valeriano; Morais, Ricardo (2020). “La política como temática de estudio en las revistas hispánicas de comunicación". Convergencia, v. 27, e14684.

https://doi.org/10.29101/crcs.v27i0.14684

Price, Vincent; Nir, Lilach; Capella, Joseph N. (2005). "Framing public discussion of gay civil unions". Public opinion quarterly, v. 69, n. 2, pp. 179-212.

https://doi.org/10.1093/poq/nfi014

Reese, Stephen D. (2001). "Framing public life: a bridging model for media research". In: Reese, Stephen; Gandy, Oscar; Grant, August. Framing public life: perspectives on media and our understanding of the social world, pp. 7-31. USA: Lawrence Erlbaum Associates. ISBN: 9780805849264 
Reese, Stephen D. (2007). "The framing project: A bridging model for media research revisited". Journal of communication, v. 57, n. 1, pp. 148-154.

https://doi.org/10.1111/j.1460-2466.2006.00334.x

Reese, Stephen D. (2018). "Preface". In: D’Angelo, Paul. Doing news framing analysis II. Empirical and theoretical perspectives. USA: Routledge, pp. 13-16. ISBN: 9781315642239

https://doi.org/10.4324/9781315642239

Rodelo, Fida V.; Muñiz, Carlos (2019). “Government frames and their influence on news framing: An analysis of cross-lagged correlations in the Mexican context". Global media and communication, v. 15, n. 1, pp. 103-119.

https://doi.org/10.1177/1742766518818862

Sádaba-Garraza, Teresa; Rodríguez-Virgili, Jordi; Bartolomé-Castro, Manuel (2012). “Propuesta de sistematización de la teoría del framing para el estudio y praxis de la comunicación política”. Observatorio (OBS*), v. 6, n. 2, pp. 109-126. http://obs.obercom.pt/index.php/obs/article/view/540

Saperas, Enric; Carrasco-Campos, Ángel (2015). “La operacionalización de la noción de framing en Journal of Communication (2009-2013): objetos de estudio, técnicas de investigación y construcción teórica". Communication \& society, v. 28, n. 4, pp. 49-66.

https://doi.org/10.15581/003.28.4.sp.49-66

Scheufele, Dietram A. (1999). "Framing as a theory of media effects". Journal of communication, v. 49, n. 1, pp. $103-122$. https://doi.org/10.1111/j.1460-2466.1999.tb02784.x

Scheufele, Dietram A. (2000). "Agenda setting, priming, and framing revisited: another look at cognitive effects of political communication". Mass communication and society, v. 3, n. 2-3, pp. 297-316.

https://doi.org/10.1207/S15327825MCS0323_07

Scheufele, Bertram T. (2004). "Framing-effects approach: A theoretical and methodological critique". Communications: The European journal of communication research, v. 29, n. 4, pp. 401-428.

https://doi.org/10.1515/comm.2004.29.4.401

Scheufele, Bertram T. (2006). "Frames, schemata, and news reporting". Communications: The European journal of communication research, v. 31, pp. 65-83.

https://doi.org/10.1515/COMMUN.2006.005

Scheufele, Dietram A.; lyengar, Shanto (2017). "The state of framing research: A call for new directions". In: Kenski, Kate; Jamieson, Kathleen. The Oxford handbook of political communication, pp. 619-632. USA: Oxford University Press. ISBN: 9780199793471

Semetko, Holli A.; Valkenburg, Patti M. (2000). "Framing European politics: A content analysis of press and television news". Journal of communication, v. 50, n. 2, pp. 93-109.

https://doi.org/10.1111/j.1460-2466.2000.tb02843.x

Shehata, Adam (2014). "Game frames, issue frames, and mobilization: Disentangling the effects of frame exposure and motivated news attention on political cynicism and engagement". International journal of public opinion research, v. 26, n. 2, pp. 157-177.

https://doi.org/10.1093/ijpor/edt034

Tankard, James W. (2001). “The empirical approach to the study of media framing”. In: Reese, Stephen D.; Gandy, Oscar H.; Grant, August E. Framing public life: perspectives on media and our understanding of the social world, pp. 95-106. USA: Lawrence Erlbaum Associates. ISBN: 9780805849264

Valera-Ordaz, Lidia (2016). “El sesgo mediocéntrico del framing en España: una revisión crítica de la aplicación de la teoría del encuadre en los estudios de comunicación”. Zer, v. 21, n. 41, pp. 13-31.

https://doi.org/10.1387/zer.16404

Van-Gorp, Baldwin (2010). "Strategies to take subjectivity out of framing analysis". In: D’Angelo Paul; Kuypers, Jim A. Doing news framing analysis: Empirical and theoretical perspectives, pp. 84-109. USA: Routledge. ISBN: 9780203864463 https://doi.org/10.4324/9780203864463

Vicente-Mariño, Miguel; López-Rabadán, Pablo (2009). “Resultados actuales de la investigación sobre framing: sólido avance internacional y arranque de la especialidad en España”. Zer, v. 14, n. 26, pp. 13-34.

https://ojs.ehu.eus/index.php/Zer/article/view/2750

Weaver, David H. (2007). "Thoughts on agenda setting, framing, and priming". Journal of communication, v. 57, n. 1, pp. 142-147.

https://doi.org/10.1111/j.1460-2466.2006.00333.x 